\title{
Optimization of Fluent Turbulence Models for Annular Diffuser
}

\author{
Nagendra Kumar Sharma
}

Assistant Professor, Mechanical Engineering Department, Amity University Madhya Pradesh, Gwalior M.P.-474005, India.

To Cite this Article

Nagendra Kumar Sharma, "Optimization of Fluent Turbulence Models for Annular Diffuser", International Journal for Modern Trends in Science and Technology, Vol. 06, Issue 06, June 2020, pp.:57-60; https://doi.org/10.46501/IJMTST060614

\section{Article Info}

Received on 30-April-2020, Revised on 24-May-2020, Accepted on 28-May-2020, Published on 05-June-2020.

\section{ABSTRACT}

A diffuser is a mechanical device used for converting the kinetic energy of flowing fluid into pressure energy. As the flow advances through the diffuser there is ongoing retardation of the flow resulting in conversion of kinetic energy into pressure energy. This is known as diffusion. Diffuser constitutes an essential part in turbo machinery and engineering structures. The present study aims at CFD analysis for the prediction of flow characteristics using various mathematical models. The annular diffuser considered in the present case has both the hub and casings are diverging with equal angles and hub angle keeping constant as $10^{\circ}$. The characteristic quantity such as velocity profiles at various sections and flow patterns have been presented for studying. Standard turbulence models are studied in the present study.

KEYWORDS: diffuser, fluent, turbulence model, Reynolds number.

Copyright (C) 2014-2020 International Journal for Modern Trends in Science and Technology

DOI: https://doi.org/10.46501/IJMTST0606014

\section{NOMENCLATURE}

$U_{\text {in }}$ Velocity at inlet

$U_{m}$ Max. Velocity

Re Reynolds number

$u_{m}$ Mean velocity with respect to inlet

$\varepsilon$ Turbulent kinetic energy dissipation rate

$\mu_{t}$ Turbulent viscosity

$k$ Turbulent kinetic energy

$\xi$ Total pressure loss co-efficient

$v$ Kinematic viscosity

$\mathrm{Sm}$ Mass added

$G_{k}$ Generation of turbulence kinetic energy

$Y_{M}$ Fluctuating dilatation in compressible turbulence

$a_{k}$ Inverse effective Prandtl numbers for $k$

$\varepsilon$, Inverse effective Prandtl numbers for $\varepsilon$

$S_{k}$ User-defined source term

$S_{\varepsilon}$ User-defined source term

\section{INTRODUCTION}

Due to the combined effects of increasing energy demand, depleting fossil fuel reserves and increasing environmental pollution, there is an urgent need for identifying alternative fuels.

Ever increasing demand of automotive vehicles for various kind of transportation, speedy depletion of crude oil resources, stern guidelines by various international agencies to control environmental pollution have inspired the worldwide researchers to carry out the research for alternative fuels for spark ignition engines which can provide the solution to these issues have been known since the use of internal combustion (IC) engines. Gasoline, alcohols and gaseous fuels are the alternative fuels for internal combustion engines [1-2]. Liquid petroleum gas (LPG) and natural gas (NG) have been used as an alternative fuels in spark ignition 
research engines and have been identified as an promising fuels of future as these fuels possess very high calorific values, lower value of pollutant emissions and improved thermal efficiency [3-5]. Similar findings have been given by other researchers also [6-7]. LPG is a byproduct of oil/mining extraction process and it is extracted from crude oil during refining process of petroleum [8-9]. LPG contains propane, butane, propene, iso-butane $\mathrm{n}$-butane in various proportions but the propane is found in maximum proportion [10-11]. The various physical and chemical properties of LPG which make it feasible alternate fuel are: higher density than air, higher calorific values, and percentage of carbon content is less, cheaper and clean burning in comparison to gasoline apart from all these qualities it can be easily adopted in spark ignition (SI) engines [12]. In comparison to conventional fuels such gasoline and diesel, compressed natural gas (CNG) has several advantages such as higher thermal efficiency and lower amount of exhaust emissions [13].

Gharehghani [4] have carried out several experimental studies to know the performance of SI engines with fuels such as gasoline or NG. From experimental results it was concluded that there was gain in thermal efficiency by amount of $5.4 \%$. There was a reduction in CO emissions but NOx emissions were higher in comparison to that of gasoline fuel. Aslam [14] also have conducted experiments using CNG fuel in SI test engines and found that there is a heavy loss of brake mean effective pressure of engine by an amount of $16 \%$, and a reduction in brake specific fuel consumption by a amount of $17-18 \%$. There was a reduction in pollutants emissions of $\mathrm{CO}, \mathrm{CO} 2$ and $\mathrm{UHC}$ in comparison to gasoline fuel engines.

In general the engine operated on CNG fuel produce less power as well as pollutant emissions particularly of NOx also increases [15]. The reduction in engine power are attributed to lower volumetric efficiency and burning of charge in comparison to liquid fuel, while rise in emission of NOx happens due to rise of combustion temperature. Shamekhi [16] have conducted several tests to know the performance and pollutant emissions of a CNG/gasoline dual fuel engines. Experimental results demonstrate that performance of bi-fuel is inferior to gasoline operated engines, volumetric efficiency of CNG operated engines decreases by an amount of $10-14 \%$ and brake power also less compared to gasoline operation engines. Another experimental result showed too much rise in NOx emissions level by an amount of 33\% in comparison to gasoline operated engines [17].

\section{EXPERIMENTAL SET UP AND PROCEDURE}

The prime aim of this experimental study is to analyze the performance of SI engines using LPG, gasoline and their mixture as fuels. A single cylinder and 4-stroke engine was used to carry out the mentioned research work. The specifications of engine used are given in table 1 .

Table 1.Engine specification

\begin{tabular}{|l|l|}
\hline Engine make & $\begin{array}{c}\text { Briggs \& Stratton } \\
\text { Model 20 I INTEK }\end{array}$ \\
\hline Displacement & $305 \mathrm{cc}$ \\
\hline Bore & $79.25 \mathrm{~mm}$ \\
\hline Stroke & $61.67 \mathrm{~mm}$ \\
\hline No of cylinder & 1 \\
\hline No of stroke & 4 \\
\hline Compression Ratio & $8.0: 1$ \\
\hline Power & $5.96 \mathrm{Kw} / 7.46 \mathrm{Kw}$ \\
\hline Torque & $19.66 \mathrm{Nm}$ @ 2800 RPM \\
\hline Cylinder & 30 degree slant \\
\hline Fuel Tank & (3.785 Liters) Polymer \\
\hline Engine cooling & Water cooled \\
\hline Muffler & $\begin{array}{c}\text { Lo-Tone Small (Super } \\
\text { Lo- Tone optional) }\end{array}$ \\
\hline
\end{tabular}

Pictorial view and schematic diagram of experimental set up are shown in figure 1 and figure 2 respectively.

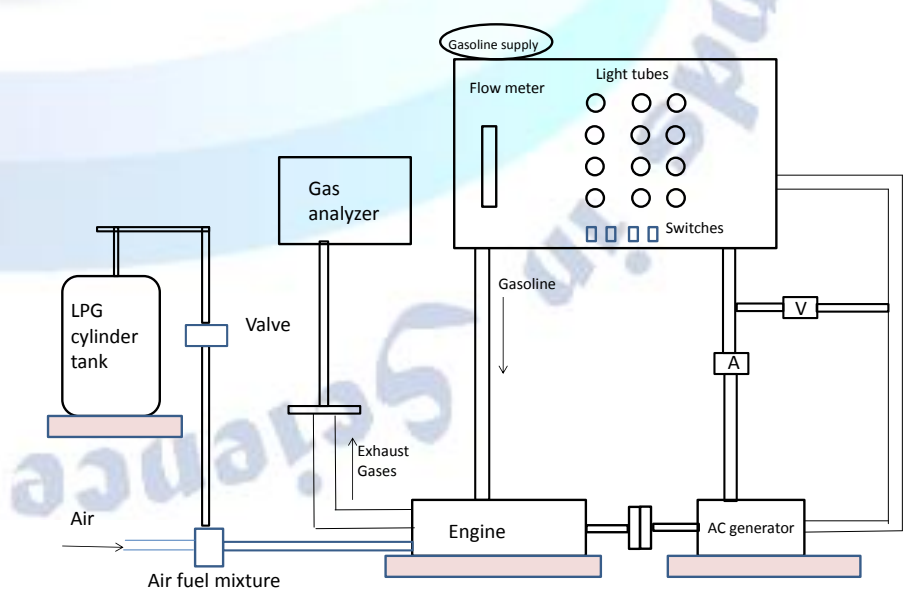

Figure 1.Schematic Diagram of Experimental Set Up.

An electrical power load circuit of electrical bulbs was connected with experimental test up to permit variation in the engine output power using the bulb switches. Tests were performed for different 
combination of engine loads for different fuels used in engine

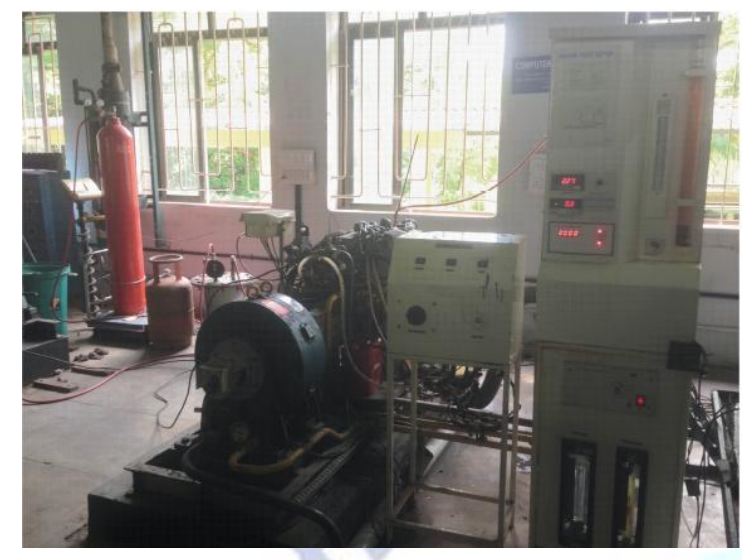

Figure 2: Pictorial View of Engine Set Up.

\section{RESULTS AND DISCUSSION}

The type of fuel used affects the performance the spark ignition engines. The combustion process and exhaust emissions are greatly influenced by the type of fuel used in spark ignition engines. The emission greenhouse gases are greatly reduced when liquefied petroleum gas (LPG) and its blends are used as a fuel in spark ignition engines. The combustion and emissions characteristics of LPG led are relatively superior to gasoline. The results obtained for engine using LPG, gasoline and their mixture fuels are analyzed below.

\section{A. THERMAL EFFICIENCY VS LOAD}

Thermal efficiency is defined as the ratio of output power to that of the chemical energy input. From the figure 3 , it is clear that as the load on the engine increases combustion efficiency increases because at part load cylinder temperature is less with the increase in load on the system, cylinder temperature and pressures both increases simultaneously.

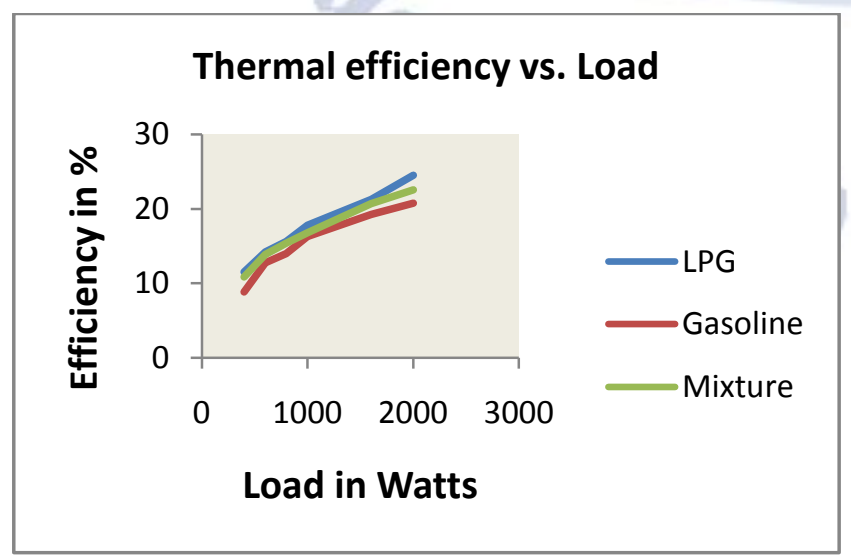

Figure 3: Thermal Efficiency vs. Load Diagram
On comparison among pure petrol, pure LPG and their mixture fuel, we find that the thermal efficiency is maximum, pure gasoline fuel engine is minimum and mixture fuel engine lies in between of these two fuels. Liquefied Petroleum Gas (LPG) is better than that of other fuels because of the following reasons:

i. Higher octane rating of the gaseous fuel allows higher compression ratio in comparison to pure gasoline mode and their mixture mode.

ii. Since LPG enters the cylinder in a gaseous state it allows more proper mixing of fuel and air. Proper mixing means proper combustion and less fuel goes unburnt into exhaust, giving more thermal efficiency.

\section{B. BRAKE SPECIFIC FUEL CONSUMPTION (BSFC) VS. LOAD}

Figure 4 shows the variation of brake specific fuel consumption (BSFC) with the load and comparison among pure LPG, pure gasoline and their blend. Though the BSFC continuously decreases with the load but fuel consumption rate is maximum in case of LPG fuel because of the following reasons:

LPG is a gaseous fuel its volume is more thus in the induction stroke less quantity of LPG is drawn. In other words it reduces the volumetric efficiency. Lower the volumetric efficiency lower the power output or we can say for the same power output fuel consumption is increased.

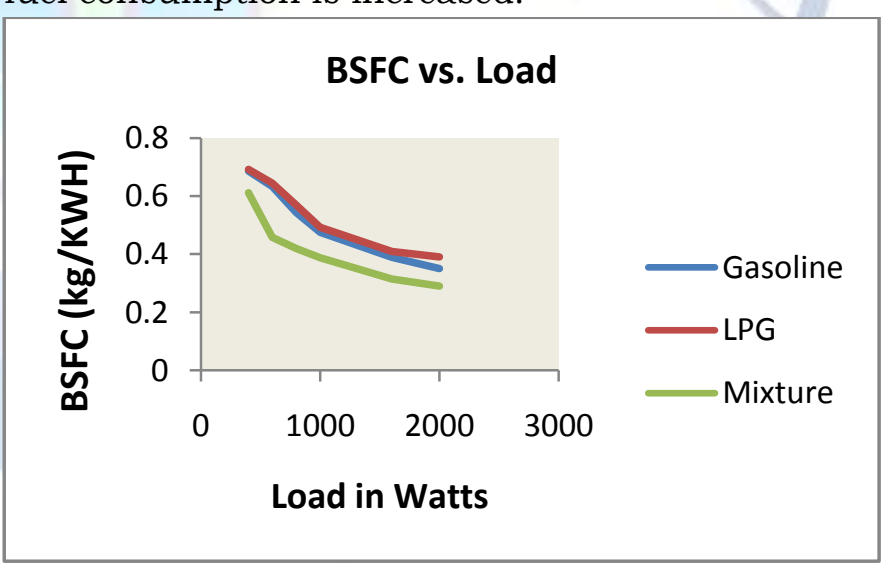

Figure 4: Brake Specific Fuel Consumption (bsfc) vs. Load Diagram

\section{CO AND HYDROCARBON (HC) EMISSIONS:}

Figure 5 shows the exhaust emissions for pure gasoline, pure LPG and mixture fuel mode.

Gasoline mode engine emits the maximum amount of hydrocarbon pollutant; HC emission of gasoline fuel engines is 3-4 times higher than the LPG \& mixture fuel mode. HC emission of LPG fuel 
engines is the lowest of all three fuel operated engines.

Figure 6 shows the CO emission for LPG fuel is the least for all three types of fuels irrespective of load. $\mathrm{CO}$ emission for gasoline fuel decreases as the load increases. But for mixture fuel emission of $\mathrm{CO}$ first decrease with load and a steep rise in emission level is recorded when load on the engines reaches a certain value.

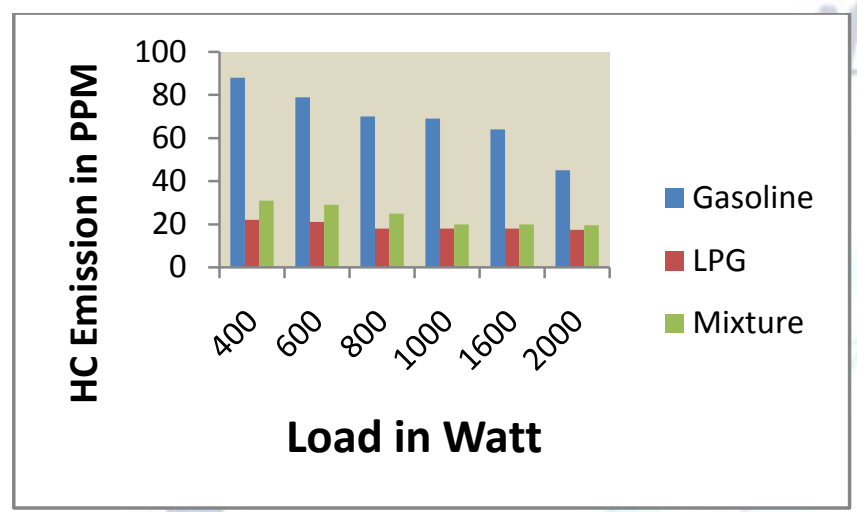

Figure 5: HC Emissions for Gasoline, $L P G$ and Mixture Fuel

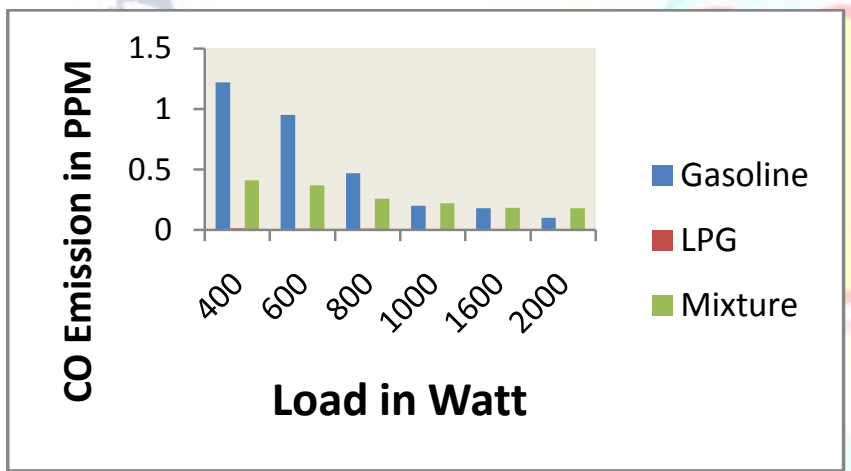

Figure 6: CO Emissions for Gasoline, LPG and Mixture Fuel

\section{CONCLUSION}

Performance and emission characteristics are greatly influenced by the type of fuel used in engine. The outcomes of this experimental work are summarized as below:

- Thermal efficiency of LPG fuel operated engine is higher than gasoline fuel engine by $14.2 \%$, and the thermal efficiency of mixture fuel lies in between LPG and gasoline fuel engine efficiency.

- Brake specific fuel consumption rate $(\mathrm{kg} / \mathrm{KWH})$ of gasoline fuel engine is less than LPG fuel engine by an amount of $3.81 \%$.

- LPG emits less pollutant in comparison to gasoline fuel, owing to its ecological worth it be suggested for use in spark ignition engines.

- Use of alternative fuels greatly reduces the HC emission. HC emissions for gasoline, LPG and mixture fuels recorded 69, 19 and $24 \mathrm{ppm}$ respectively. $\mathrm{CO}$ emissions for $\mathrm{LPG}$, gasoline and mixture fuel engines are $0.85,5.2$ and $2.7 \%$ respectively.

\section{REFERENCES}

[1] T Thrings R. Alternative Fuels for spark-ignition engines. SAE Technical Paper 831685,1983; 4715-25.

[2] Chen H, He J, Zhong X. Engine combustion and emissions filled with natural gas: a review. J Energy inst 2018:1-14.

[3] Tuner, Martin. Combustion of alternative vehicle fuels in internal combustion engines, 2015.

[4] Ghaarehghani A, Hosseini R, Mirsalim M, Yusaf T. A comparative study on the first and second law analysis and performance characteristics of a spark ignition engine using either natural gas or gasoline. Fuel 2015;158:488-493.

[5] Shamekhi A, Khatibzadeh N, Shamekhi A H. Performance and emissions characteristics investigation of a Bi-Fuel SI engine fuelled by CNG and gasoline. ICES-2006;ASME 2006; 393-400.

[6] Muillo S, Miguez J L, Lopez Gonzalez L M, Granada E, Moran J C. LPG: Pollutant emission and performance enhancement for spark-ignition four strokes outboard engines. Applied thermal engineering 2005;25(13):1882-1893.

[7] Shivprasad K V., Chitragar P, Kumar G N. Effect of hydrogen addition on combustion and emissions characteristics of a spark ignition engine. An experimental study SAE Technical Paper 2015; No. 2015-01-1684.

[8] Beer, Tom, Tim Grant, David Williams, Harry Watson. Fuel-cycle greenhouse gas emissions from alternative fuels in Australian heavy vehicles. Atmospheric Environmental 2002; 36(4):753-763.

[9] Poulton, Mark L. Alternative fuels for road vehicles, Bellerica, MA: Computational Mechanics Publications 1994.

[10] Baron, Jerzy, Elzbieta M, Bulewicz W, Zukowski, Stanislaw Kanderfer, MalgorzataPilawska. Combustion of hydrocarbon fuels in a bubbling fluidized bed. Combustion and Flame 2002; 128(4):410-421.

[11] Dagaut P, Hadj Ali K. Kinetics of oxidation of a LPG blend mixture in a JSR: Experimental and modeling study. Fuel 2003; 82(5): 475-480.

[12] Yeom, Kitae, Jinyoung Jang, ChoongsikBae. Homogeneous charge compression ignition of LPG and gasoline using variable valve timing in an engine. Fuel 2007;86(4):494-503.

[13] Thiruvengadam A, Besch M, Padmanaban V, Pradhan S, Demirgok B. Natural gas vehicles in heavy-duty transportation-A review. Energy Policy 2018;22:253-259.

[14] Aslam M, Masjuki H, Kalam M, Abdesselam H, Mahlia T, Amalina M. An experimental investigation of CNG as an alternative fuel for a retrofitted gasoline vehicle. Fuel 2006; 85:717-724.

[15] Jones A, Evans R. Comparison of burning rates in a natural-gas-fueled spark ignition engine. J Eng Gas Turbines Power 1985; 107(4); 908-913.

[16] Shamekhi A, Khatibzadeh N. A comprehensive comparative investigation of compressed natural gas as an alternative fuel in a Bi-fuel spark ignition engine. Iran $\mathrm{J}$ ChemChemEng 2008; 27:73-83.

[17] Zeng K, Huang Z, Liu B, Liu I, Jiang D, Ren Y, et al. Combustion characteristics of a direct-injection NG engine under various fuel injection timings. ApplThermEng 2006;26(8-9):806-813. 